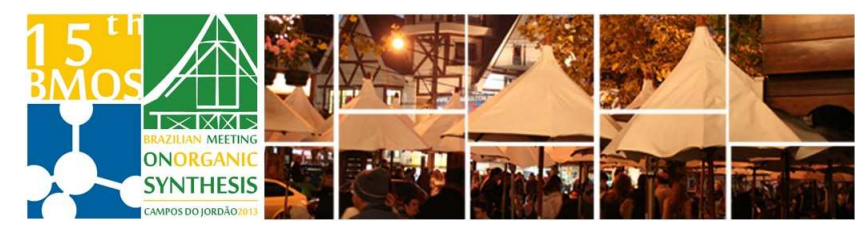

\title{
Synthesis of new ionophilic SNS ligands and their Ru(II) complexes
}

\section{Gabriela I. Matiello, ${ }^{*}$ Jairton Dupont, Günter Ebeling}

Laboratory of Molecular Catalysis, Institute of CHemistry, UFRGS, Av. Bento Gonçalves 9500, Agronomia,

$$
\begin{aligned}
& \text { 91501-970, Porto Alegre-RS, Brazil } \\
& \text { * gabriela.matiello@ufrgs.br }
\end{aligned}
$$

Keywords: SNS ligands, ionophilic ligands and Ru(II) complexes.

\section{INTRODUCTION}

Ruthenium complexes have many applications among them that their use in advanced material synthesis and heterogeneous catalysis. Developing the ligand is of great importance and this is of influence on the yield and selectivity of reaction, and especially to allow reuse of the catalyst. Taskspecific ionic liquids (TSILs) are commonly used as ligands for metallic complexes, due to their easily tunable properties and, specifically, ionophilic ligands can provide the advantages of strong interaction with ionic liquids as solvents, which reduces the loss of catalyst and its subsequent reuse. ${ }^{1}$ Tridentate pincer ligands containing the SNS moiety $\left(\mathbf{S C H}_{2} \mathrm{CH}_{2} \mathbf{N H C H}_{2} \mathrm{CH}_{2} \mathbf{S}\right)$ were selected mainly for application in ester hydrogenation/ dehydrogenation reactions. $^{2}$

\section{RESULTS AND DISCUSSION}

In this work we obtained new ionophilic SNS ligands of which one was used to obtain a novel complex of $\mathrm{Ru}$ (II). The synthetic route to obtain the precursor reagents of the ligands, $P_{1}$ and $P_{2}$, is presented in Scheme 1:

1.

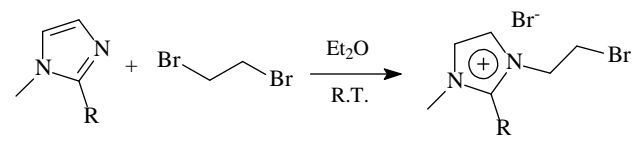<smiles>[R]c1n(CCC)cc[n+]1[Z6]</smiles><smiles>[R]c1c(C(C)O)ccn1CCSC(N)=[NH2+]</smiles>

3.

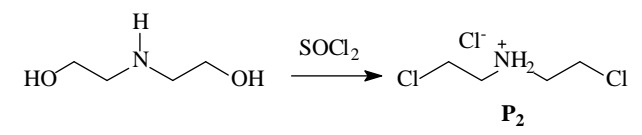

Scheme 1. Synthesis of precursor reagents for the ligands, $\mathrm{P}_{1}$ and $\mathrm{P}_{2} . \mathrm{R}=\mathrm{H}, \mathrm{CH}_{3}$.

Reaction 1 and 3 were performed according to know procedures reported earlier. ${ }^{3}$ By the way, the synthesis of the ligands were performed, in $60 \%$ overall isolated yield, in one-pot reaction in water, starting with the hydrolysis of isothiouronium salt $P_{1}$, followed by addition of $\mathrm{P}_{2}$ and then anion metathesis to $\mathrm{NTf}_{2}^{-} \mathrm{PF}_{6}^{-}$, as outlined in Scheme 2:

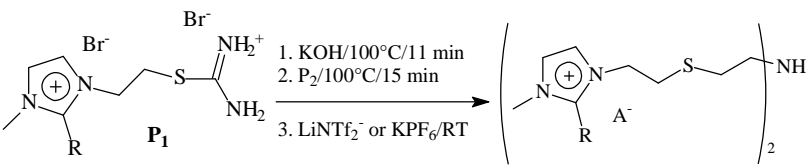

Scheme 2. lonophilic SNS ligands. $\mathrm{R}=\mathrm{H}, \mathrm{CH}_{3} \cdot \mathrm{A}^{-}=\mathrm{NTf}_{2}$ $\mathrm{PF}_{6}^{-}$.

The $\mathrm{Ru}(\mathrm{II})$ complex (Figure 2) was obtained reacting $\mathrm{RuCl}_{2}\left(\mathrm{PPh}_{3}\right)_{3}$ with the ligand $\left(\mathrm{R}=\mathrm{H}, \mathrm{A}^{-}=\mathrm{NTf}_{2}{ }^{-}\right)$in methanol reflux with an isolated yield of $47 \%$.

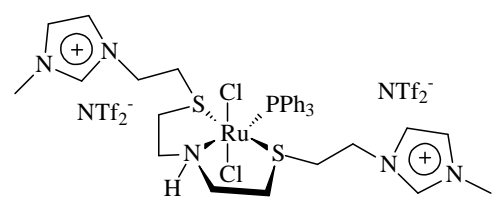

Figure 1. $\mathrm{Ru}(\mathrm{II})$ complex with $S N S$ ligand: $\mathrm{R}=\mathrm{H}$ and $A^{-}=\mathrm{NTf}_{2}^{-}$.

The ligands and the complex were preliminarily characterized using $1 \mathrm{H} / 13 \mathrm{C}$ NMR. More complexes with different metals and the synthesized ligands are being obtained in our research group.

\section{CONCLUSION}

A class of new ionophilic SNS ligands was synthesized through simple reactions and a new complex of $\mathrm{Ru}$ (II) was successfully obtained. It is expected that these compound possess potential application in ester hydrogenation/dehydrogenation reactions.

\section{ACKNOWLEDGEMENTS}

The authors wish to thanks CAPES for financial support.

\section{REFERENCES}

${ }^{1}$ Consorti, C. S.; Aydos, G. L. P.; Ebeling, G.; Dupont, J. Org. Lett. 2008, 10,237

${ }^{2}$ Spasyuk, D.; Smith, S.; Gusev, D. G. Angew. Chem. Int. Ed. 2013, 52, 1.

${ }^{3}$ a) Field, L. D.; Messerle, B.A.; Vuong, K. Q.; Turner, P. Organometallics 2005, 24, 4241. b) Mann, F.G. J. Chem. Soc. 1934, 461. 